\title{
Erratum to: Preface: Proceedings of the Vth International Workshop on Biology and Culture of the Tench (Tinca tinca) (L. 1758), Ceresole d'Alba (Italy), September 29-October 3, 2008
}

Ewa Kamler · Laura Gasco · Jacek Wolnicki

Published online: 9 January 2010

(C) Springer Science+Business Media B.V. 2010

Erratum to: Rev Fish Biol Fisheries

DOI 10.1007/s11160-009-9147-9

(L. 1875) appearing in title phrase should be read as

(L. 1758).

The online version of the original article can be found under doi:10.1007/s11160-009-9147-9.

E. Kamler $(\bowtie) \cdot J$. Wolnicki

Inland Fisheries Institute, Zabieniec, 05-500 Piaseczno,

Poland

e-mail: kamler@infish.com.pl

L. Gasco

Dipartamento di Scienze Zootecniche, Via L. da Vinci,

Grugliasco, TO, Italy 